\title{
Supporting the district nurse to consolidate advanced clinical skills.
}

BAIN, H. and MOGGACH, A.

2019

This document is the Accepted Manuscript version of a Published Work that appeared in final form in British Journal of Community Nursing, copyright (C) MA Healthcare, after peer review and technical editing by the publisher. To access the final edited and published work see https://doi.org/10.12968/bjen.2019.24.4.153 


\title{
Supporting the district nurse to consolidate advanced clinical skills.
}

\author{
Dr Heather Bain, Academic Strategic Lead 1 \\ Alison Moggach, Nurse Consultant Primary Care 2
}

\section{Robert Gordon University \\ 2 NHS Grampian}

Corresponding author Heather Bain, heather.bain@rgu.ac.uk 01224262634

Despite evidence that district nursing is valued by the population with which it works and that the policy agenda supports healthcare at home (Scottish Government 2017) it is well recognised that the district nursing service in some areas is in crisis (Maybin et al 2016). It is also acknowledged that the practices of the district nurse across the UK vary considerably. The north east of Scotland led the way in district nursing in 2013, moving education and service delivery beyond the traditional district nurse model to a supporting education at Master's level and integrating some advanced level skills. However, this move has not been without challenges for some individuals. With district nurses being lone workers and existing district nurses not practicing advanced skills, student district nurses had challenges to consolidate their skills. At this point the education was more advanced than the practice experience available.

Concurrently as this was being recognised NHS Grampian employed two advanced practice nurse consultants, one for primary care and another for acute. These appointments resulted in a practice development project where the principles of the transforming nursing roles involved the development of an Advanced Practice Academy concept to support robust initial preparation of advanced skills for all health care professionals under the supervision of skilled and experienced mentors. A collaborative approach with Robert Gordon University and NHS Grampian involved medical colleagues to support key components of developing competency in advanced practice.

As part of this workstream the district nurses in a region of Grampian were targeted to support the consolidation of their advanced skills, including high level decision making, clinical examination and history taking, interpreting the significance of findings, developing a differential diagnosis, treatment plan and develop prescribing competence. Fortnightly the district nurses in question participated in a clinic initially supported by nurse consultant and a district nurse practice teacher with advanced practice skills including prescribing. Over a period of time the individuals have developed their competence and confidence.

This model to support the consolidation of advanced skills has now been replicated all over NHS Grampian. In addition to the two nurse consultants, experienced advanced nurse practitioners are employed as fellows within the Advanced Practice Academy. All are working closely with identified District Nurses who do not yet have advanced skills and the student district nurses to support clinical competence and enhance care in the community setting. This model has not been without its challenges in that some individuals are not accepting of the changing role of the district nurse and in that it is resourceful to maintain 
this high level of supervision in practice. However, it is recognised once advanced clinical skills are embedded within nursing practice in the community, it will become part of routine

The blended learning approach along with the consolidation in practice has produced significant outcomes for the public and access to services in this Health Board area. The partnership approach has resulted in positive feedback from both service users and medical colleagues. Traditional boundaries have been crossed and person centred care by the right person in the right place at the right time has been embraced. Interestingly the CNO paper published in 2017 (Scottish Government 2017) confirms the requirement of district nurses in Scotland to embrace and develop in this way to meet the needs of the population. This advanced practice academy model is one way to support the learning in practice as district nurse roles advance with developments in service needs

\section{References}

MAYBIN. J, CHARLES, A and HONEYMAN, M. 2016. Understanding quality in district nursing services Learning from patients, carers and staff London: The King's Fund.

SCOTTISH GOVERNMENT, 2017. Paper 3 The district nurse role in integrated community nursing teams. Edinburgh: Scottish Government 